\title{
Positive Relationships Between Human Impact and Biodiversity: the Case of the Fire-Bellied Toad (Bombina bombina) in Europe
}

\author{
Volodymyr Tytar \\ Department of animal monitoring and \\ conservation \\ I. I. Schmalhausen Institute of Zoology \\ NAS of Ukraine \\ Kyiv, Ukraine \\ vtytar@gmail.com
}

\author{
Oksana Nekrasova \\ Department of animal monitoring and \\ conservation \\ I. I. Schmalhausen Institute of Zoology \\ NAS of Ukraine \\ Kyiv, Ukraine \\ oneks22@gmail.com
}

\author{
Mihails Pupins \\ Department of Ecology \\ Daugavpils University, Institute of Life \\ Sciences and Technologies \\ Daugavpils, Latvia \\ mihails.pupins@gmail.com
}

\begin{abstract}
Habitat modification affects amphibians indirectly by reducing energy reserves and energy allocated to growth and reproduction, and by affecting population dynamics and viability. Marginal populations of amphibians in Latvia and Ukraine are particularly vulnerable. On the other hand, several studies have shown a positive relationship between human density and biodiversity, indicating that species-rich areas and human enterprises quite often co-occur. Therefore, both positive and negative correlations between human population and species richness may be expected. For a better understanding of what constitutes suitable habitat we used a habitat modeling approach, where modeling can be used for revealing species ecological requirements and relationships between the distribution of species and predictive variables, as well as the importance of each variable in model building. Here we employed maximum entropy (MaxEnt) niche modeling, as a tool to assess potential habitat suitability (HS) for amphibians in Europe, making special emphasis on anthropogenic impact. We used 2474 georeferenced point data (783 - B. bombina occurrence, and to compare results 1691 - L. vulgaris), including results of our field investigations in Latvia and Ukraine. The predictor variables used for modelling the toad species $\mathrm{HS}$ suitability were of climate derived from the WorldClim database (19 bioclimatic variables). Human impact was assessed by the Human Footprint (HF), produced through an overlay of a number of global data layers that represent the location of various factors presumed to exert an influence on ecosystems: human population distribution, urban areas, roads, navigable rivers, and various agricultural land uses. Using the Spearman rank correlation, a low, however statistically significant positive correlation $(p<0.05)$, was found between the predicted $\mathrm{HS}$ and the $\mathrm{HF}$.
\end{abstract}

Keywords-Bombina bombina, niche modeling (MaxEnt), Human Footprint (HF).

\section{INTRODUCTION}

Human civilization has had a negative impact on biodiversity, particularly since the industrial revolution. Overfishing and hunting, the destruction of habitats through agriculture and urban encroachment, the use of pesticides and herbicides, and the release of other toxic compounds into the environment have all been damaging, particularly for vertebrates [1]. Amongst the vertebrates, amphibians, because of their sensitivity and general dependence on both terrestrial and aquatic habitats, are considered to be particularly vulnerable [2]. Habitat modification affects amphibians indirectly by reducing energy reserves and energy allocated to growth and reproduction, and by affecting population dynamics and viability $[3,4]$.

On one hand, human activities, in particular the alteration of habitats [5] are major causes of biodiversity loss [6], but on the other several studies have shown a positive relationship between human density and biodiversity, indicating that species-rich areas and human enterprises quite often co-occur [7]. This relationship can be mediated by productivity, because high primary productivity is correlated with both species richness and human settlement. Therefore, both positive and negative correlations between human population and species richness may be expected.

For a better understanding of what constitutes suitable habitat and how this could be related to human impact we used a habitat modeling approach [8], where modeling can be used for revealing species' ecological requirements (quantified in terms of habitat suitability, HS) and exploring the relationships between HS and human impact. In this paper we exemplify our approach by focusing on the European fire-bellied toad, Bombina bombina (Linnaeus, 1761) for which the destruction of wetlands by human encroachment is the most serious threat to populations, leading to decline or extinction of this species from many areas of West and Central Europe [9]. The IUCN (Red List) Status of the species is "Least Concern (LC)", it is listed under the Bern Convention (Annex 2), included to the Red Data Books of Lithuania and Latvia under the category "Rare".

For comparative purposes we also consider the and the Common newt, Lissotriton vulgaris (Linnaeus, 1758). On large areas, L. vulgaris is not threatened, however, some populations are declining or extinct due to anthropogenic causes, especially under urban conditions

Print ISSN 1691-5402

Online ISSN 2256-070X

http://dx.doi.org/10.17770/etr2019vol1.4099

(C) 2019 Volodymyr Tytar, Oksana Nekrasova, Mihails Pupins.

Published by Rezekne Academy of Technologies.

This is an open access article under the Creative Commons Attribution 4.0 International License. 
[10]. The IUCN (Red List) Status of the species is "Least Concern (LC)" and it is listed under the Bern Convention (Annex 3).

\section{Materials AND METHOdS}

Occurrence data collection

We digitized presence survey data, including results of our field investigations in Latvia and Ukraine, to generate the occurrence data used in the modeling. Georeferencing (in Google Earth) was accomplished for 783 point data of B. bombina occurrence, and 1691 for L. vulgaris.

\section{Environmental data}

In most cases environmental predictors are selected based on the availability and experience that the variables show correlation with the species distribution [11]. Biotic factors, which are challenging to model explicitly, may nonetheless be implicitly represented in the model because they strongly correlate with abiotic factors [12]. In such circumstances it is reasonable to assume that biotic processes, that lead to the species realized distribution, may be captured by the relationship between the environmental predictor variables of abiotic character and the modeled species' occurrence patterns and it is reasonable to consider modeling the distribution only with selected environmental variables and meaningful climatic factors identified to be of most importance to amphibians [13]. In this work, we used climatic predictor data, sourced from the Worldclim dataset [14]. The Worldclim variables represent annual trends (e.g. mean annual temperature, annual precipitation) and extreme limiting environmental factors (e.g. temperature of the coldest and warmest months, precipitation of the wettest or driest quarter) and are known to influence species distributions.

As proxies for human disturbance of natural systems we used Human Footprint (HF) maps compiled from remotely-sensed and bottom-up survey information on eight variables measuring the direct and indirect human pressures on the environment globally [15]. Data on human pressures were acquired or developed by the authors for: 1) built environments, 2) population density, 3) electric infrastructure (night light), 4) crop lands, 5) pasture lands, 6) roads, 7) railways, and 8) navigable waterways. Pressures were then overlaid to create the standardized HF maps.

\section{Model building}

The Maxent software (v.3.3.3k) was utilized for modeling, using the default settings. Maxent, unlike other distributional modeling techniques, uses only presence and background data instead of presence and absence data. This method has been shown to perform well in comparison with alternative approaches [16]. Logistic output format was used to describe the probability of presence [17], which is a continuous HS range between 0 (unsuitable) and 1 (the most suitable). Statistical data was analyzed using the PAST software package [18].

\section{RESULTS AND DISCUSSION}

Using the Spearman rank correlation, low, however statistically significant positive correlations $(p<0.05)$ were found between the predicted for the toad and newt species HS and the standardized HF index, and some of the pressures mentioned above (Table I). The ascending logarithmic trendline in Fig. 1 shows this positive relationship in the case of the HF index for $B$. bombina.

TABLE I. SPEARMAN RANK CORRELATIONS BETWEEN PREDICTED FOR BOMBINA BOMBINA AND LISSOTRITON VULGARIS HABITAT SUITABILITY AND HUMAN DISTURBANCE

\begin{tabular}{|c|c|c|}
\hline \multirow{2}{*}{$\begin{array}{c}\text { Human distur- } \\
\text { bance }\end{array}$} & \multicolumn{2}{|c|}{ Species } \\
\cline { 2 - 3 } & $\begin{array}{c}\text { Bombina bom- } \\
\text { bina }\end{array}$ & $\begin{array}{c}\text { Lissotriton vul- } \\
\text { garis }\end{array}$ \\
\hline HF index & 0.167 & 0.302 \\
\hline $\begin{array}{c}\text { Built environ- } \\
\text { ments }\end{array}$ & n.s. & 0.238 \\
\hline Night light & n.s. & 0.337 \\
\hline $\begin{array}{c}\text { Population } \\
\text { density }\end{array}$ & 0.150 & 0.500 \\
\hline Pasture lands & -0.166 & 0.141 \\
\hline Crop lands & 0.181 & n.s. \\
\hline \multicolumn{2}{|c|}{$*$ n.s. - statistically not significant } \\
\hline
\end{tabular}

A fairly large correlation of 0.5 was found between the predicted habitat suitability for the newt and population density. A graph built by using the method of the least squares curve fitting shows this relationship (Fig. 2), where increasing scores of human population density (at least up to the score of 8) enhance the HS for the species. In other words, places more densely populated by humans are more favourable for the wellbeing of the Common newt, although the most heavily populated places (characterized by scores 9 and 10) seem to be losing some of their attractiveness.

The relationships between human factors and biodiversity are important to assess the risk of extinction as human pressures are often related to large changes in biological diversity. However, the literature often shows contradictory results. Previous studies report that human influence may affect species' spatial distribution both negatively and positively [19].

For the considered in this study amphibian species a positive association with human-impacted areas was found. However, according to AmphibiaWeb [9, 10], the European fire-bellied toad in comparison to the Common newt differ in their ability to cope with human pressure. The fire-bellied toad is rare in urban environments and the lack of significant correlations of HS with built environments and the intensity of nighttime lights (a correlate with socioeconomic indicators and economic development) supports this view. Other established by correlation relationships point out the importance of rural areas for the toad, namely crop land (the association is positive), but the association is negative in the case of pasture land. Indeed, landscapes dominated by pasture 
can be harsh environments for amphibians. The absence of sheltering and shading structures (e.g. trees and shrubs) can increase air and soil temperature and decrease humidity, directly and negatively affecting amphibian performance [20]. In addition, cattle graze shoreline and terrestrial vegetation and deposit nitrogenous waste in wetlands. There is growing evidence that agricultural practices that allow cattle access in wetlands may negatively affect some amphibian species [21, 22], and this may apply to the European fire-bellied toad.

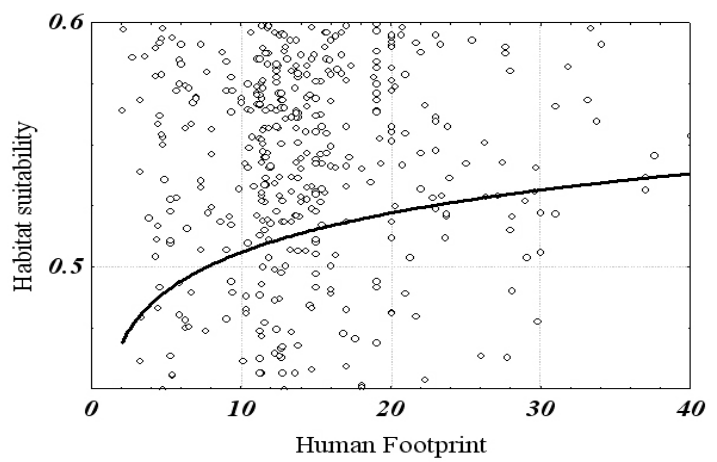

Fig. 1. A logarithmic trendline showing the relationship between the Human Footprint index and predicted habitat suitability for B. bombina.

Contrary to the toad, the Common newt often is found in landscapes altered by humans, including large cities, and its ability for synanthropization is considered moderate. In fact, this difference is reflected in the established Spearman rank correlations, showing a greater association of the newt with human-impacted areas, primarily with densely populated areas, night light and built-up environments, and in the last turn with pasture land, and no significant association with crop land.

The reason for co-occurrence of suitable habitat and human enterprises may be that though human population is concentrated in regions critical for amphibians, there is still a substantial amount of intact habitat in many of these regions. On the other hand, amphibians have been found breeding in a variety of habitats that are substantially different from their former pristine breeding habitats [23], so native wildlife can often adapt to novel and altered habitats, given suitable conditions. In North America and in Australia, for instance, human infrastructure provided beneficial environments to some amphibian species [24].

Our assumption is that human-constructed habitats such as ponds, fish farming facilities etc., housing, roads and waterways can enhance biodiversity. According to our observations, in dry areas, the presence of artificial, man-made ponds and reservoirs is of great importance (Fig. 3) for the hosting of such synanthropic amphibian species as Bufotes viridis [25] and pioneer species as $B$. bombina $[26,27,28]$ etc.. Besides the synanthropization of animals, an increase in the number of anomalies in amphibians has been observed for over more than a 20-year period in Ukraine (1996-2018), and a statistically significant correlation of the number of anomalies in amphibians with the anthropogenic impact (assessed by the HF) was found $[29,30]$. Finally, B. bombina and oth- er amphibians can be subjected to invaders, for instance the Chinese sleeper $[31,32,33,34]$ and alien freshwater turtles [35].

Human infrastructure can encourage species to colonize urban areas by creating ecological corridors and networks to circumvent obstacles, thereby providing access to favourable habitats $[1,28]$. This is a phenomenon that perhaps is much more widespread than thought before.

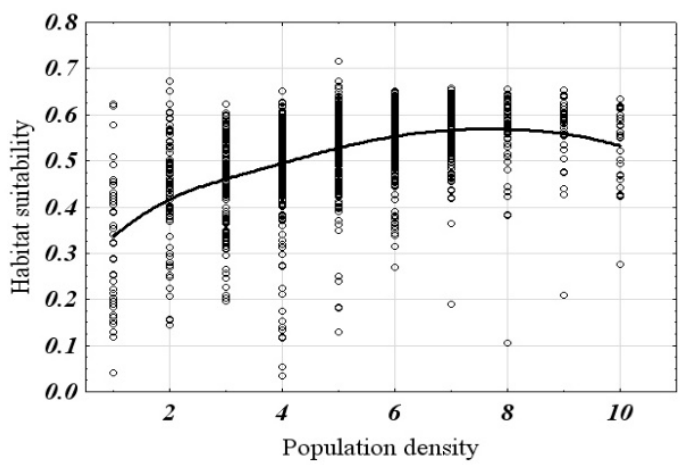

Fig. 2. Relationship between scores of human population density and predicted habitat suitability for $L$. vulgaris.

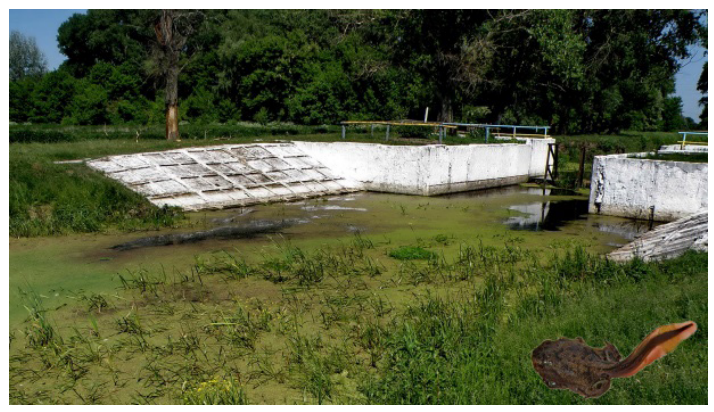

Fig. 3. Amelioration channel - breeding habitat for B. bombina (River Trubizh, Kyiv region, Ukraine: biotope and juv. B. bombina).

\section{Conclusions}

We used a habitat modeling approach where modeling has successfully been used for revealing species' ecological requirements and exploring the relationships between habitat suitability and human impact. For both considered in this study amphibian species (the European fire-bellied toad and the Common newt) a positive association with human-impacted areas was found. From conventional knowledge it is clear that both species differ in their ability to cope with human pressure and in our approach we have arrived with the same conclusion, but in a quantified manner. Our assumption is that human infrastructure can enhance biodiversity, a phenomenon that perhaps is much more widespread than thought.

\section{AcKNowledgments}

The study was conducted in accordance with legislation of Latvia and Ukraine. We thank Daugavpils University for support and A. Pupina for her many-years leadership in research of $B$. bombina in Latvia. 


\section{REFERENCES}

[1]. P. Hunter, "The human impact on biological diversity. How species adapt to urban challenges sheds light on evolution and provides clues about conservation," EMBO Rep. Apr, 8(4), pp. 316-318, 2007.

[2]. P. J. Bishop, A. Angulo, J. P. Lewis et al., "The Amphibian Extinction Crisis - what will it take to put the action into the Amphibian Conservation Action Plan?," Sapiens 5(2), pp. $97-$ 111, 2012.

[3]. J. A. López, P. A. Scarabotti, R. Ghirardi, "Amphibian trophic ecology in increasingly human-altered wetlands," Herpetological Conservation and Biology, 10(3), pp. 819-832, 2015.

[4]. V. Tytar, O. Nekrasova, A. Pupina, M. Pupins, O. Oskyrko, "Long-term bioclimatic modelling the distribution of the firebellied toad, Bombina bombina (Anura, Bombinatoridae), under the influence of global climate change," Vestnik Zoologii, vol. 52(4), pp. 341-348, 2018.

[5]. J. M. Kiesecker, A. R. Blaustein, L. K. Belden, "Complex causes of amphibian population declines," Nature. 410, N 6829, pp. 681-684, 2001.

[6]. T. M. Brooks, R. A. Mittermeier, C. G. Mittermeier, et al. "Habitat loss and extinction in the hotspots of biodiversity," Conservation Biology, 16, N 4, pp. 909-923, 2002.

[7]. G. W. Luck, "A review of the relationships between human population density and biodiversity," Biological Reviews, 82 , N 4, pp. 607-645, 2007.

[8]. A. T. Peterson, "Uses and requirements of ecological niche models and related distributional models," Biodiversity Informatics, 3, pp. 59-72, 2006.

[9]. AmphibiaWeb, "Bombina bombina: Fire-Bellied Toad" <http:// amphibiaweb.org/species/2041> University of California, Berkeley, CA, USA. Accessed Mar 2, 2019, 1999a.

[10]. AmphibiaWeb, "Lissotriton vulgaris: Smooth Newt <http:// amphibiaweb.org/species/4303> University of California, Berkeley, CA, USA. Accessed Mar 2, 2019, 1999b.

[11]. A. Guisan, N. E. Zimmerman, "Predictive habitats distribution models, in ecology," Ecological Modelling, 135, N 2, pp. 147 $186,2000$.

[12]. J. Soberón, M. Nakamura, "Niches and distributional areas: concepts, methods and assumptions," Proceedings of the National Academy of Sciences USA, 106, Supplement 2, pp. 19644-19650, 2009

[13]. M. Girardello, M. Griggio, M. J. Whittingham, et al., "Models of climate associations and distributions of amphibians in Italy," Ecological Research, 25, N 1, pp. 103-111, 2009.

[14]. R. J. Hijmans, S. E. Cameron, J. L. Parra, P. G. Jones and A. Jarvis, "Very high resolution interpolated climate surfaces for global land areas," International Journal of Climatology, vol. 25(15), pp. 1965-1978, 2005.

[15]. O. Venter, E. W. Sanderson, A. Magrach et al., "Global terrestrial Human Footprint maps for 1993 and 2009," Sci Data. 23;3:160067. doi: 10.1038/sdata.2016.67, Aug 2016.

[16]. J. Elith, C. H. Graham, R. P. Anderson, et al., "Novel methods improve prediction of species' distributions from occurrence data," Ecography, 29, N 2, pp. 129-151, 2006.

[17]. S. J. Phillips and M. Dudik "Modeling of species distributions with Maxent: new extensions and a comprehensive evaluation," Journal of Ecography, vol. 31, no. 2, pp. 161-175, 2008. https:// doi.org/10.1111/j.0906-7590.2008.5203.x

[18]. Ø. Hammer, D. A. T. Harper, P. D. Ryan, "PAST: Paleontological statistics software package for education and data analysis," Palaeontologia Electronica, 4 (1), pp. 9, 2001
[19]. J. Young, A. Watt, P. Nowicki, et al., "Towards sustainable land use: identifying and managing the conflicts between human activities and biodiversity conservation in Europe," Biodiversity and Conservation, 14, N 7, pp. 1641-1661, 2005.

[20]. F. R. Silva, T. A. L. Oliveira, J. P. Gibbs, D. C. Rossa-Feres, "An experimental assessment of landscape configuration effects on frog and toad abundance and diversity in tropical agro-savannah landscapes of southeastern Brazil," Landsc Ecol., 27, pp. 87-96, 2012. $10.1007 / \mathrm{s} 10980-011-9670-7$

[21]. A. C. Schmutzer, M. J. Gray, E. C. Burton, D. L. Miller, "Impacts of cattle on amphibian larvae and the aquatic environment," Freshwater Biology, 53, pp. 2613-2625, 2008. doi:10.1111/ j.1365-2427.2008.02072.x

[22]. R. M. Pelinson, M. V. Garey, D. C. Rossa-Feres, "Effects of Grazing Management and Cattle on Aquatic Habitat Use by the Anuran Pseudopaludicola mystacalis in Agro-Savannah Landscapes," PLoS One., 11(9): e0163094. 2016.

[23]. M. J. Rubbo, J. M. Kiesecker, "Amphibian breeding distribution in an urbanized landscape," Conservation Biology, 19, N 2, pp. 504-511, 2005.

[24]. M. J. Tyler, R. Wassersug, B. Smith," How frogs and humans interact: Influences beyond habitat destruction, epidemics and global warming," Applied Herpetology, 4, N 1, pp. 1-18, 2007.

[25]. O. D. Nekrasova, V. M. Tytar, "Modeling of the spatial structure of green toad populations (Bufotes viridis (Laurenti, 1768)) and its correlation with anthropogenic habitat," in Proceedings of the third international Scientific and practical conference "Regional aspects of floristic and faunistic research" Putila, Chernivtsi region, Ukraine, pp. 35-37, 2016. (In Russian).

[26]. S. L. Kuzmin, A. Pupina, M. Pupins, G. Trakimas, "Northern border of the distribution of the red-bellied toad Bombina bombina," Zeitshrift fur Feldherpetologie, vol. 15 (2), pp. 215 228, 2008.

[27]. A. Pupina, M. Pupins, "The new data on distribution, biotopes and situation of populations of Bombina bombina in the south-east part of Latvia," Acta Biologica Universitatis Daugavpiliensis, vol. 8 (1), pp. 67-73, 2008.

[28]. A. Pupina, M. Pupins, "A new Bombina bombina L. population "Demene" in Latvia, Daugavpils area," Acta Universitatis Latviensis, vol. 273, Biology, pp. 47-52, 2007.

[29]. O. Nekrasova, O. Marushchak, V. Tytar, O. Oskyrko, "Current trends in the manifestation of external morphological anomalies in representatives of the herpetofauna of Ukraine under anthropogenic influence and climate change," in the 4rd International Symposium on EuroAsian Biodiversity. SEAB, Kiev, Ukraine, pp. 101, 2018.

[30]. V. M. Tytar, O. D. Nekrasova, and A. Yu. Marushchak, "Ecological and Geographical Gis-Analysis of Anomalies in Amphibians of Ukraine," in The Second International conference "Amphibian and reptiles anomalies and pathology: methodology, evolutionary significance, monitoring and environmental health", KnE Life Sciences, pp. 42-48. 2018.

[31]. A. Pupina, M. Pupins, O. Nekrasova, V. Tytar, I. Kozynenko, O. Marushchak, "Species distribution modelling: Bombina bombina (Linnaeus, 1761) and its important invasive threat Perccottus glenii (Dybowski, 1877) in Latvia under global climate change," Journal of Environmental Research, Engineering and Management, vol.74, No.4, pp. 79-86, 2018. DOI 10.5755/j01. erem.74.4.21093V.

[32]. A. Pupina, M. Pupins, A. Skute, Ag. Pupina, A. Karklins, "The distribution of the invasive fish amur sleeper, rotan Perccottus glenii Dybowski, 1877 (Osteichthyes, Odontobutidae), in Latvia," Acta Biologica Universitatis Daugavpiliensis, vol. 15 (2), 329-341, 2015.

[33]. M. Pupins, A. Pupina, "Reciprocal predation between preserved and invasive species: adult Bombina bombina predate young whitebaits of alien fish Perccottus glenii," Acta Biologica Universitatis Daugavpiliensis, vol. 18 (2), pp. 217-223, 2018.

[34]. M. Pupins, A. Pupina, "Invasive fish Perccottus glenii in biotopes of Bombina bombina in Latvia on the north edge of the fire-bellied toad's distribution," Acta Biologica Universitatis Daugavpiliensis, Suppl. 3: 82-90, 2012.

[35]. M. Pupins, A. Pupina, "First records of 5 allochthonous species and subspecies of Turtles (Trachemys scripta troostii, Mauremys caspica, Mauremys rivulata, Pelodiscus sinensis, Testudo horsfieldii) and new records of subspecies Trachemys scripta elegans in Latvia," Management of Biological Invasions, vol. 2,

pp. 69-81, 2011. 